\title{
Desire for prenatal gender disclosure among primigravidae in Enugu, Nigeria
}

\author{
This article was published in the following Dove Press journal: \\ Patient Preference and Adherence \\ II March 2015 \\ Number of times this article has been viewed
}

\author{
Tochukwu C Okeke' \\ Jamike O Enwereji' \\ Onyemaechi S Okoro' \\ Eric S Iferikigwel \\ Lawrence C Ikeako \\ Cyril C Ezenyeaku \\ Charles O Adiri' \\ 'Department of Obstetrics \\ and Gynaecology, University \\ of Nigeria Teaching Hospital, Enugu, \\ Nigeria; ${ }^{2}$ Department of Obstetrics \\ and Gynaecology, Anambra State \\ University Teaching Hospital, Awka, \\ Nigeria
}

Background: Prenatal gender disclosure is a nonmedical fetal ultrasonography view, which is considered ethically unjustified but has continued to grow in demand due to pregnant women's requests.

Objective: The aim of this study was to determine the proportion of primigravidae who want prenatal gender disclosure and the reasons for it.

Methods: This was a descriptive cross-sectional study of randomly selected primigravidae seen at Enugu Scan Centre. The women were randomly selected using a table of random numbers. Results: Ninety percent (225/250) of 250 primigravidae who fulfilled the criteria for inclusion in this study wanted to know the gender of their unborn baby, while $10 \%(25 / 250)$ declined gender disclosure. Furthermore, 62\% (155/250) of primigravidae had preference for male children. There was statistically significant desire for male gender $(P=0.0001)$. Statistically significant number of primigravidae who wanted gender disclosure did so to plan for the new baby $(P=0.0001)$, and those that declined gender disclosure "leave it to the will of GOD" $(P=0.014)$.

Conclusion: Ninety percent of primigravidae wanted gender disclosure because of plans for the new baby, personal curiosity, partner and in-laws' curiosity; moreover, some women wanted to test the accuracy of the findings at delivery and $62 \%$ of primigravidae had preference for male children. In view of these results, gender disclosure could be beneficial in this environment. Keywords: gender disclosure, prenatal ultrasonography, pregnant women, Enugu, Nigeria

\section{Introduction}

Prenatal gender disclosure is a nonmedical fetal ultrasonography procedure, which is considered ethically unjustified but has continued to grow in demand due to pregnant women's requests. ${ }^{1}$ This practice is tolerated because there is no evidence or scientifically proven harm to the fetus. ${ }^{1,2}$ Gender identification can be done by ultrasonography more reliably from 16 weeks of pregnancy, ${ }^{1-3}$ and by the 20 th week of gestation, the accuracy is close to $97 \%{ }^{2}$

The obvious reasons for gender detection are medical and social. ${ }^{4}$ Medical reasons for prenatal gender disclosure include X-linked disorders, ambiguous genitalia, testicular feminization syndrome, and assignment of zygosity in twin pregnancy. ${ }^{4-6}$ However, gender preference by the society is assuming an important role. ${ }^{3,7}$ Gender preference varies from tribe to tribe, from place to place, and from society to society. Preference for male children is influenced by sociodemographic, sociocultural, religious, economic, emotional, and obstetric factors. ${ }^{3,7}$

Disclosure of fetal gender to pregnant women may be associated with either a positive or a negative attitude. ${ }^{8}$ Worldwide, studies have shown preference for male children over females in Nigeria, Asian countries, India, People's Republic of China, and South Korea. ${ }^{9-12}$ Recurring reasons for the preference for male children are to continue with
Correspondence: Tochukwu C Okeke Department of Obstetrics and Gynaecology, University of Nigeria Teaching Hospital, Ituku-Ozalla, Enugu, Nigeria

Email tcokeke20I4@yahoo.com 
family lineage, to take care of parents in old age, and to act as supports. This has resulted in strong gender discrimination in towns and tribes in relation to food and education. ${ }^{13,14}$ In places where male children are more desirable, gender disclosure during ultrasound examination has been outlawed due to female feticide. ${ }^{15}$ The fear of selective abortion and feticide of an unwanted gender has led to restrictions or complete ban on prenatal gender disclosure in some countries. ${ }^{16}$ This is not applicable to Nigeria. Reasons for prenatal gender disclosure in Nigeria are multiple and varied. ${ }^{5,10}$

A lot has been said about prenatal gender disclosure worldwide. In some countries, there are strict laws barring gender disclosure to combat gender selection and feticide. In some countries, gender disclosure is regarded as a human rights issue that should not be denied upon request. In Nigeria, there are no laws guiding prenatal gender disclosure.

Previous studies in Nigeria have shown that the majority number of women desire to know the gender of their fetus during prenatal ultrasound scan. ${ }^{2,9,10,17}$ This desire is equally expressed by women in Uganda, ${ }^{6}$ People's Republic of China, ${ }^{18,19}$ Pakistan, ${ }^{20}$ and Nepal. ${ }^{21}$

Worldwide, the consequences of prenatal gender disclosure are preference for sons, gender-selective abortion, ${ }^{18,19}$ and postnatal gender selection, with resultant high mortality of female children through deliberate neglect. ${ }^{8}$

The objective of this study was to determine, among primigravidae in Enugu, Nigeria, the proportion of women who desire prenatal gender disclosure and the reasons for it.

\section{Subjects and methods}

This was a descriptive cross-sectional study of randomly selected primigravidae seen at the Enugu Scan Centre for routine prenatal ultrasonography between January 1, 2014 and June 30, 2014. The women were randomly selected using table of random numbers. This center is a private specialist ultrasound service located at 104 Agbani Road, Enugu.

The inclusion criteria were primigravidae at 16 weeks or more who presented for routine obstetric ultrasound scan and who voluntarily consented to participate in this study after counseling. The exclusion criteria were primigravidae who came for emergency obstetric ultrasound scan with a complicated pregnancy and who voluntarily refused to participate in the study after counseling. Those that fulfilled the inclusion criteria were asked by the sonologist during the scan if she wanted to know the gender of the fetus by saying YES or NO. Those that wanted to know fetal gender received disclosure if determined, while those that declined had their wishes respected (upheld) and their reasons documented.
Calculated minimum sample size was 163 based on the formula $\left[P \times Q(E / d)^{2}\right]$ (where $P=$ the probability of choosing a male or female baby $=50 \% ; Q=100-P=100-50=50$; $E=$ chosen error margin at $95 \%$ confidence interval $=5 \%$; and $d=$ standard error at $95 \%$ confidence interval which is 1.96). The probability of choosing a male or female baby is equal to $50 \%$, at $5 \%$ chosen error margin and 1.96 standard error at $95 \%$ confidence interval. However, 250 patients were recruited. Therefore, a total of 250 primigravidae who sought routine obstetric ultrasonography at Enugu Scan Centre formed the sample size (respondents) in this study. After assurance of confidentiality, informed consent was taken from each respondent, after explaining the purpose of the study.

\section{Ultrasound scan for prenatal gender disclosure}

The ultrasound scan for this study was performed with Simens SL-1 machine using transabdominal 5.0 MHz probe. Fetal gender was identified by the presence of the sonological features of external genitalia at the perineum. The male fetus was recognized by the presence of the scrotal sac as a rounded echogenic structure separated by an echogenic median raphe and the phallus as an echogenic cylindrical structure. The female fetus was recognized by the two labial folds, which are seen as two oblong echogenic structures separated by an echo-free area.

Data collection instrument was a 12-item semistructured self-completion questionnaire designed to cover data extraction from the respondents in line with the purpose of this study. The questionnaire was administered to the respondents after obtaining permission and consent from the management of the Enugu Scan Centre to carry out the study. The information obtained from the respondents were sociodemographic characteristics (age, ethnic group, occupation, educational level, and religion), indications for the scan, past obstetric history, history of index pregnancy, last menstrual period, any preference for gender, and reasons for requesting prenatal gender disclosure.

Data collected were analyzed using the Statistical Package for Social Sciences software, version 16 (SPSS Inc, Chicago, IL, USA). Descriptive and inferential statistics were calculated for all the variables in the study. Chi-square test was applied for quantitative variables. A $P$-value $<0.05$ was considered statistically significant.

\section{Results}

A total of 250 primigravidae fulfilled the criteria for inclusion in this study. The age range was $16-45$ years with a 
mean age of 27 years. Ibo women were the majority, with 91.2\% (228/250), while other major tribes, such as Hausa (3.2\%) and Yoruba (1.6\%), and other minor ethnic groups constituted $4.0 \%$ of the study population. The predominant religion was Christianity (98\%). Women with primary education alone comprised $54 \%$ of the sample, while women with postprimary education up to tertiary education constituted $44 \%$. Housewives constituted $44 \%$ of the study population, while civil servants and traders constituted $38 \%$ and $10 \%$, respectively. These data are shown in Table 1.

Out of the 250 primigravidae who met the inclusion criteria, $90 \%$ (225/250) wanted to know the fetal gender of their unborn baby, while $10 \%$ (25/250) did not want to know the gender of their unborn baby. The most common reason for wanting disclosure of their unborn baby was to plan for the new baby $(52.4 \% ; 118 / 225)$, personal curiosity $(27.6 \%$; $62 / 225)$, and partner's curiosity $(13.8 \% ; 31 / 225)$. Reasons for declining disclosure of unborn baby's gender were to leave the decision to the will of God $(60 \% ; 15 / 25)$, prefer to know the gender after delivery $(12 \% ; 3 / 25)$, one should not be overambitious $(4 \% ; 1 / 25)$, and anxiety over risk of error on ultrasonography $(4 \% ; 1 / 25)$. These details are shown in Tables 2 and 3.

Table I Sociodemographic characteristics of antenatal women

\begin{tabular}{llll}
\hline $\begin{array}{l}\text { Sociodemographic } \\
\text { factor }\end{array}$ & Frequency & $\%$ & Significance \\
\hline Age group of the respondents & 7 & & \\
$\quad \leq 20$ & 145 & 58.0 & Age group 2I-30, \\
$2 \mathrm{I}-30$ & 95 & 38.0 & \\
$3 \mathrm{I}-40$ & 3 & 1.2 & \\
$\geq 4 \mathrm{I}$ & 250 & 100 & \\
Total & & & \\
Tribe & 228 & 91.2 & Ibo, $P=0.000 \mathrm{I}$ \\
Ibo & 8 & 3.2 & \\
Hausa & 4 & 1.6 & \\
Yoruba & 10 & 4.0 & \\
Others & 250 & 100 & \\
Total & & & \\
Religion & 245 & 98.0 & Christianity, \\
Christianity & 3 & 1.2 & $P=0.000 \mathrm{I}$ \\
Islam & 2 & 0.8 & \\
Pagan & 250 & 100 & \\
Total & & & \\
Occupation & 110 & 44.0 & Housewives, \\
Housewives & 95 & 38.0 & $P=0.000 \mathrm{I}$ \\
Civil servants & 15 & 6.0 & \\
Students & 5 & 2.0 & \\
Farmers & 25 & 10.0 & \\
Traders & 250 & 100 & \\
Total & & & \\
\hline
\end{tabular}

Table 2 Preference for prenatal disclosure, gender preference, and level of education

\begin{tabular}{llll}
\hline & Frequency & $\%$ & Significance \\
\hline Prenatal disclosure & & & \\
Want to know & 225 & 90 & - \\
Do not want to know & 25 & 10 & \\
$\quad$ Total & 250 & 100.0 & \\
Gender preference & & & \\
$\quad$ Male & 155 & 62.0 & Desire for male gender, \\
Female & 78 & 31.2 & $P=0.000$ I \\
Any gender & 17 & 6.8 & \\
$\quad$ Total & 250 & 100.0 & \\
Education & & & \\
$\quad$ No formal education & 5 & 2.0 & Primary education, \\
Primary education & 135 & 54.0 & $P=0.000$ I \\
Secondary education & 80 & 32.0 & \\
Tertiary education & 30 & 12.0 & \\
Total & 250 & 100.0 & \\
\hline
\end{tabular}

In this study, $62 \%(155 / 250)$ primigravidae had preference for male children, $31.2 \%$ (78/250) primigravidae had preference for female children, while $6.8 \%(17 / 250)$ had no preference and awaited the delivery of child of any gender from God. Reasons for preference for male children were for protection of marriage, for propagation of the family name, and as a source of income. The predominant reason for pregnant women not being interested in disclosure of fetal gender is that it should be left to God's will.

\section{Accuracy of gender prediction}

The accuracy of prenatal gender prediction in this study was $100 \%$. Prenatal gender determination with ultrasonography

Table 3 Reasons for wanting/not wanting to know fetal gender on prenatal ultrasonography

\begin{tabular}{|c|c|c|c|}
\hline Variable & Frequency & $\%$ & Significance \\
\hline \multicolumn{4}{|c|}{$\begin{array}{l}\text { Reasons for wanting to know fetal gender on prenatal ultrasonography } \\
(\mathrm{n}=225 ; 90 \%)\end{array}$} \\
\hline Plan for new baby & 118 & 52.4 & Plan for new baby, \\
\hline Personal curiosity & 62 & 27.6 & $P=0.000 \mathrm{I}$ \\
\hline Partner's curiosity & 31 & 13.8 & \\
\hline In-laws want to know & 14 & 6.2 & \\
\hline Total & 225 & 100 & \\
\hline \multicolumn{4}{|c|}{$\begin{array}{l}\text { Reasons for not wanting to know fetal gender on prenatal ultrasonography } \\
(\mathrm{n}=25 ; 10 \%)\end{array}$} \\
\hline Leave to "the will of God" & 15 & 60 & Leave to "the will \\
\hline $\begin{array}{l}\text { Prefer to know the gender } \\
\text { after delivery }\end{array}$ & 3 & 12 & of GOD”, $P=0.014$ \\
\hline $\begin{array}{l}\text { Anxiety over risk of error } \\
\text { on ultrasonography }\end{array}$ & I & 4 & \\
\hline Should not be overambitious & I & 4 & \\
\hline Personal reasons & 4 & 16 & \\
\hline Do not want to know & 1 & 4 & \\
\hline Total & 25 & 100 & \\
\hline
\end{tabular}


was based on the identification of specific fetal anatomical features of the external genitalia at the perineum at 16 weeks or more during pregnancy. These fetal anatomical features are well described under ultrasound scan for prenatal gender disclosure in the methodology in this study.

\section{Discussion}

In this study, $90 \%$ of the women wanted to know the fetal gender at prenatal ultrasonography. This finding is comparable to the results of Maaji et $\mathrm{al}^{2}$ in 2010 and the Boston study by $\mathrm{Nze}^{22}$ in 1996 . This finding is higher than that reported in earlier studies by Ekele et al, ${ }^{5}$ Adekanle et al, ${ }^{9}$ Okonta et al, ${ }^{10}$ and Enakpene et $\mathrm{al}^{17}$ all in Nigeria. The reasons for such a high percentage $(90 \%)$ of women wanting to know the fetal gender could be that the study population was literate, about $98 \%$ of them having primary school education and above. Only $2 \%$ did not have formal education. The women were enlightened and curiosity was high to know the fetal gender. It could be that some of the women wanted to probably test the accuracy of the findings after delivery.

Ten percent of women in this study declined to know the fetal gender. This finding is similar to the study reported by Maaji et $\mathrm{al}^{2}(5.5 \%)$ but not consistent with the studies by Kansal et $\mathrm{al}^{23}$ and Shukar-ud-din et $\mathrm{al}^{3}$ which reported $61.8 \%$ and $68.6 \%$, respectively, of women who declined to know the fetal gender. Reasons offered for the refusal to know the fetal gender in this study were to leave it to the will of God, anxiety over the risk of error on ultrasonography and its negative impact on women's psychological health, and the notion that one should not be overambitious.

In this study, $62 \%$ of women were curious to know the fetal gender. This finding is lower than the report of Mubuuke $^{6}$ among Ugandan women, wherein all women wanted to know the fetal gender to enable them to go shopping and prepare for their new arrival. ${ }^{6}$ Our finding is also not in agreement with the study conducted by Ekele et $\mathrm{al}^{5}$ who reported curiosity in $18 \%$ of women.

It is generally accepted that preference for male children is widespread worldwide and is associated with strong discrimination against women. ${ }^{3}$ In this study, $62 \%$ of women preferred to have a male baby. This finding is consistent with the $58.8 \%$ result reported by Vadera et $\mathrm{al}^{24}$ and $58.6 \%$ reported by Ohagwu et $\mathrm{al}^{8}$ but higher than that $(15.2 \%)$ reported by Shukar-ud-din et al. ${ }^{3}$ Reasons for preference for male children were socioeconomic, protection of their marriages, and propagation of the family name. ${ }^{3,8}$

Male gender preference is strongly perceived by Igbo women who form $91.2 \%$ of the study population. Preference for male children is also more predominant in South Asia and in developing countries such as Bangladesh, the People's Republic of China, India, Pakistan, Korea, and Taiwan. ${ }^{3,25}$ There is a stronger perception of male gender preference among Igbo women irrespective of age, education, parity, and the number of male and female children already in the family. ${ }^{8}$

The limitations of this study are restriction of this study to women in Enugu and the small sample size used in this study. Women who sought antenatal care in Enugu were literate and that might have influenced the results observed in this study. However, the findings may not be truly representative of Igbo women and calls for caution while interpreting the findings with these limitations in mind.

\section{Conclusion}

Ninety percent of primigravidae desire gender disclosure because of plans for the new baby, personal curiosity, partner and in-laws' curiosity, and to test the accuracy of the findings at delivery; $62 \%$ of primigravidae had preference for male children. In view of these, gender disclosure could be beneficial in this environment.

\section{Acknowledgments}

We thank the respondents and the management of the Enugu Scan Centre for their kind assistance in permitting us to use their center for data collection in this study.

\section{Disclosure}

The authors report no conflicts of interest in this work.

\section{References}

1. Leung JI, Pang SM. Ethical analysis of non-medical fetal ultrasound. Nurs Ethics. 2009; 16:637-646.

2. Maaji SM, Ekele BA, Bello SO, Morhason-Bello IO. Do women want disclosure of fetal gender during prenatal ultrasound scan? Ann Afr Med. 2010;9:11-14.

3. Shukar-ud-din S, Ubaid F, Shahani E, Saleh F. Reasons for disclosure of gender to pregnant women during prenatal ultrasonography. Int $J$ Womens Health. 2013;5:781-785.

4. Shipp TD, Shipp DZ, Bromley B, et al. What factors are associated with parents desire to know the sex of their unborn child? Birth. 2004;31:272-279.

5. Ekele BA, Maaji SM, Bello SO, Morhason-Bello IO. Profile of women seeking fetal gender at ultrasound in a Nigerian obstetric population. Ultrasound. 2008;16:119-202.

6. Mubuuke AG. An exploratory study of the views of Ugandan women and health practitioners on the use of sonography to establish fetal sex. Pan Afr Med J. 2011;9:36.

7. Edmeades J, Pande RP, Falle T, Krishnan S. Son preference and sterilization use among young married women in two shuns in Bengahuru city, India. Glob Public Health. 2011;6:407-420.

8. Ohagwu CC, Eze CU, Eze JC, Odo MC, Abu PO, Ohagwu CI. Perception of male gender preference among pregnant Igbo women. Ann Med Health Sci Res. 2014;4:173-178. 
9. Adekanle DA, Bello TO, Odu OO. Predictors of request for antenatal sex determination among the pregnant women in Osogbo, Nigeria. Niger J Med. 2007;16:322-325.

10. Okonta PI, Okogbenin SA, Adeoye-Sunday I. Pregnant Nigerian Women's view of her prenatal sex determination. J Obstet Gynaecol. 2004;24:875-877.

11. Gudex C, Nielsen BL, Medsen M. Why women want prenatal ultrasound in normal pregnancy. Ultrasound Obstet Gynaecol. 2006;27: $145-150$.

12. Westley SB, Choe MK. How Does Son Preference Affect Populations in Asia. Hawaii: Analysis from East-West Centre; 2007:84.

13. Mahalingam R. Culture, ecology and beliefs about the gender in son preference cast groups. Evol Hum Behav. 2008;28:319-329.

14. Uddo JJ, Anah MU, Ochigbo SO, Etuk IS, Ekanem AD. Neonatal morbidity and mortality in Calabar, Nigeria: a hospital-based study. Niger J Clin Pract. 2008;11(3):285-289.

15. Edward H, Thomson N. Social and practical implications of fetal sex determination using ultrasound. Ultrasound. 2012;20:49-53.

16. Kishwar M. When daughters are unwanted sex determination tests in India. Manushi. 1995;86:15-22.

17. Enakpene CA, Morhason-Bello IO, Morinho AO, et al. Clients reasons for prenatal ultrasonography in Ibadan, South West of Nigeria. BMC Womens Health. 2009;9:12.

18. Nie JB. Non-medical sex-selective abortion in China: ethical and public policy issues in the context of 40 million missing females. Br Med Bull. 2011;98:7-20.
19. Zhou C, Wang XL, Zhou XD, Hesketh T. Son preference and sexselective abortion in China: informing policy options. Int $J$ Public Health. 2012;57:459-465.

20. Qadir F, Khan MM, Medhin G, Prince M. Male gender preference, female gender disadvantage as risk factors psychological morbility in Pakistani women of childbearing age - a life course perspective. $B M C$ Public Health. 2011;11:745.

21. Chetri UD, Ansari I, Bandary S, Adhikari N. Sex preferences among mothers delivery at Patan Hospital. Kathmandu Uni Med J. 2011;9: 229-232.

22. Nze DA. Ultrasound determination of fetal gender: accuracy and social implications. East Afr Med J. 1996;73:225-227.

23. Kansal R, Maroof KA, Bansal R, Parashar P. A hospital based study on knowledge, attitude and practice of pregnant women on gender preference, sex determination and female feticide. Indian J Public Health. 2010;54:209-212.

24. Vadera BN, Joshi UK, Unadakat SV, Yadav BS. Study on knowledge, attitude and practices regarding gender preference and female feticide among the pregnant women. Indian J Community Med. 2007;32:300-301

25. Wongboonsin K, Ruffolo VP. Sex preference for children in Thailand and some other South East Asian Countries. Asia Pac Popul J. 1995; 10:43-62.
Patient Preference and Adherence

\section{Publish your work in this journal}

Patient Preference and Adherence is an international, peer-reviewed, open access journal that focuses on the growing importance of patient preference and adherence throughout the therapeutic continuum. Patient satisfaction, acceptability, quality of life, compliance, persistence and their role in developing new therapeutic modalities and compounds to optimize

\section{Dovepress}

clinical outcomes for existing disease states are major areas of interest for the journal. This journal has been accepted for indexing on PubMed Central. The manuscript management system is completely online and includes a very quick and fair peer-review system, which is all easy to use. Visit http://www. dovepress.com/testimonials.php to read real quotes from published authors. 